\title{
Language and Cognitive Impairments Associated with Encephalitis
}

\author{
Raphiq Ibrahim \\ The Edmond J. Safra Brain Research Center for the Study of Learning Disabilities, \\ Department of Learning Disabilities, University of Haifa, \\ Israel
}

\section{Introduction}

Although the gross deficits of diseases of the brain have been extensively characterized, few studies have examined their associated cognitive impairments. Interest has focused recently on the language and cognitive impairments that develop following encephalitis. The symptoms of impairments following the disease were determined mainly by examining hospital records of those previously admitted with cerebral inflammation, who were assessed at least 20 months after discharge to detect motor, speech and language, and other cognitive (attention, memory, and non-verbal ability) impairments. This chapter deals with language and cognitive disturbances based on the literature and a published case study of a proficient bilingual man suffering from brain damage following intracranial hemorrhage and epileptic seizures related to herpes encephalitis (Ibrahim, 2009a). This case showed somewhat different symptomatologies on language ability measures in first language and second languages.

\section{Background}

Encephalitis is an inflammation of the brain usually caused by a virus, or, in rare cases, by bacteria. It is typically caused by one of three groups of viruses: the herpes viruses including chickenpox, Epstein-Barr (that causes mononucleosis), and herpes simplex (that causes cold sores); viruses transmitted by insects, like West Nile virus, and the germs that cause Lyme disease and Rocky Mountain Spotted Fever; and viruses that cause childhood infections like measles, mumps, and German measles.

Widespread immunization against encephalitis and other diseases has brought a marked decrease in their occurrence, but they continue to appear, sporadically and in miniepidemics. While most cases of encephalitis are mild and symptoms last for only a short time, severe life-threatening cases can develop. Symptoms of mild cases include fever, headache, poor appetite, loss of energy, and/or a general feeling of malaise. In more severe cases patients develop high fever, severe headache, sensitivity to light, nausea and vomiting, stiff neck, confusion, sleepiness, difficulty waking, and/or unconsciousness. As encephalitis affects the brain, severe cases can sometimes develop epileptic seizures and intracranial hemorrhages that lead to difficulties with muscle movement and coordination, speech disorders, cognitive deficits and learning disabilities. These symptoms of encephalitis may last months or longer. 
Risk factors for the development of language (speech) and cognitive deficits after illnesses of the brain have been described (Holding, Stevenson, et al., 1999; Carter, Murira, et al., 2003), but the studies generally classified patients as having impairments or not, rather than differentiating between impairments of different functions.

\subsection{Language and cognitive impairments}

Cognitive and language impairments following encephalitis have not been extensively described in the literature. Language and speech impairments develop mostly in children with severe encephalopathy (generally those with hypoglycaemia or elevated intracranial pressure), and in cases of long-term nutritional deprivation (Walther \& Ramaekers, 1982). These deficits might be a manifestation of global cerebral damage rather than injury to a specific area of the brain, given the wide range of risk factors associated with language. In these cases, language deficits overlap with impairments in other cognitive abilities and motor functions, and impairment in one ability may affect the others. For example, because language, cognitive abilities, memory and attention overlap, impairments in language and other cognitive functions may arise as side-effects of impaired memory and attention (which has sizeable verbal components in terms of instructions, teaching elements, or response formats), while other language difficulties may stem from impaired motor function (Pennington, et al., 2004).

With regard to cognitive impairment after encephalitis, researchers suggested that only episodes of epileptic seizures increased the risk of cognitive impairment (Holding et al., 1999; Boivin, 2002). Based on clinical and epidemiological studies, they concluded that only in cases of hypoglycaemia and absence of hyperpyrexia is there impairment of cognition (Holding et al., 1999).

Idro and colleagues (2006) also reported this finding, stating that "hypoglycaemia was associated with impairment of non-verbal functioning but instead of absence of hyperpyrexia, we observed that children who failed to mount a febrile response (no history of fever before admission) had an increased risk of developing memory impairment" (p.146). Researchers described in detail the neurological and cognitive assessments: tests of attention (visual search), memory tests based on the Rivermead Behavioural Memory Test for Children (Wilson \& Aldrich, 1991), non-verbal functioning (construction tasks such as copying shapes using drawings, blocks, or sticks to assess the coordination of complex cognitive tasks), and a parental rating of behaviour problems (Holding et al., 1999). Speech and language assessments included all major areas of language: receptive grammar and vocabulary, lexical semantics (expressive vocabulary), syntax/morphology, pragmatics (language use), phonology, higher level language, and word finding (Carter, et al., 2003). A classification of "speech and language impairment" was defined as an impairment level score on two or more of the language assessments, while a designation of "impairment in other cognitive functions" described children with impairment level performance in any one of attention, memory, or non-verbal functioning (Carter, et al., 2005a; Carter, et al., 2005b).

Idro et al. (2006) found that seizures are common precipitators of admission. Thus, it is possible that each episode cumulatively increases the risk of focal neurological damage, and that on subsequent visits, patients present with multiple seizures, focal neurological signs, and motor impairment (Ido, et al., 2004). Due to their diffuse nature, deficits are likely to involve more than one function (Holding et al., 1999), and survivors of the more severe 
forms are likely to suffer greater neuronal damage. Some cognitive functions such as language may be affected by external factors such as the child's nutritional state at the time of the encephalopathy (Neumann, et al., 1992; Johnston, et al., 1987).

In a systematic review of neurological and cognitive impairments associated with common central nervous system infections, Carter, Neville and Newton (2003) found those exposed to acute bacterial meningitis $(\mathrm{ABM})$ had a higher prevalence of long-term impairments. The risk of impairments after $\mathrm{ABM}$ was greatest for, but not confined to, those who had acute neurological complications such as coma. This chapter presents the performance of a bilingual patient (M.H.) suffering from brain damage following intracranial hemorrhage related to herpes encephalitis disease (Ibrahim, 2009a). His performance on several linguistic tasks in his first language (L1-Arabic) and second language (L2-Hebrew) displayed somewhat different symptomatologies in the two languages. There was a dissociation between the two languages in terms of the magnitude of the errors and the error types, suggesting aphasic symptoms in the two languages, with Hebrew (L2) being more impaired. As we will see, this dissociation was better explained by damage at the lexical level rather than at the semantic level of representation. We further explore whether this specific impairment is also present in the patient's L2 in order to elucidate the organization of a second language in the brain.

\section{Case report}

M.H. is a 41-year-old, right-handed male high school biology teacher. He is a native speaker of Arabic, was born in Israel, and acquired Hebrew language in $4^{\text {th }}$ grade. He used Hebrew in his academic, professional and private settings, and before contracting encephalitis at the age of 39 , his Hebrew competence was reported by his bother to be very high. He was a university graduate, where the language of instruction was Hebrew, and had passed the Hebrew proficiency exam required at enrollment.

In May, 2004, M.H. was brought to the hospital with sudden onset of fever and confusion. Following an initial examination in which he was found to be febrile, confused and disoriented, he was sent to a regional hospital (Rambam Medical Center). A cereberal spinal fluid specimen was positive for herpes simplex virus type 1 (HSV-1) by polymerase chain reaction testing on the third day of hospitalization, and antiviral therapy (acyclovir) was begun. Two days later he suddenly developed a severe headache, vomiting and disturbance of consciousness. Radiological investigations showed severe, massive intracranial hemorrhage in the left temporal lobe, compressing the central line of the brain contralaterally. On the same day, he underwent left temporal craniotomy for removal of the lesion mass, following which a CT scan demonstrated moderate hemorrhage and encephalomyelitis in the left temporal lobe and right frontal subdural hemorrhage. His fever returned to normal 12 hours after surgery but he became lethargic. He was sent to Bet Levenstein Rehabilitation Hospital where he stayed two months, during which he developed an acute onset of a neurological deficit, epileptic status with left temporal focus, and amnestic aphasia.

Upon admission to Bet Levenstein, M.H. was active, cooperative, and oriented to place, situation and time. His visual fields and auditory abilities were intact. His spontaneous language production was non-fluent, with grammatical disruptions and common anomic states. The subtest from the Western Aphasia Battery (WAB; Kertesz, 1982) and the Boston 
Naming Test (BNT; Kaplan, et al., 1983) in Arabic and Hebrew yielded results consistent with mild to moderate amnestic aphasia (Albert, et al., 1981). Throughout this period he received intensive language therapy.

\subsection{Neuropsychological tests}

Neuropsychological tests were conducted in January 2006, 32 months after hospitalization in Bet Levenstein, and included visual and language abilities.

\subsubsection{Visual abilities}

To rule out the possibility that the patient's symptoms were caused by the right frontal hemorrhage, his performance was assessed on tasks that tap visuospatial and frontal difficulties. The results showed normal visual ability good copying and construction abilities on the Rey Complex Figure test (Meyers \& Meyers, 1995). Cognitive flexibility was measured by a Wisconsin Card Sorting Test (WCST) (Heaton, et al., 1993). His capacity for non-verbal abstraction was close to normal for his age, consistent with his intact visual perception and reasoning skills.

\subsubsection{Language abilities}

\subsubsection{Phonological/phonetic abilities}

M.H. was given three auditory tasks, as described by Luria (1970): (a) counting the letters in individual spoken words, (b) counting syllables in an individual spoken word, and (c) synthesizing words from individually pronounced letters (i.e., recognizing an auditorally spelled word). His performance on these tasks was found to be dependent on word length, with better performance on short words (three to five letters). Both Arabic and Hebrew are languages with deep orthography: they do not have one-to-one correspondence between letters and sounds, because most Arabic and Hebrew vowels are not instantiated as letters. This is probably reflected in the relatively similar performance by M.H. in the two languages. It was observed that M.H. counted phonemes instead of letters. Interestingly, in naming Hebrew phonemes, M.H. used the Arabic terms, referring to the sounds rather than the real names of these letters. For example, when presented with the letter he said [ba] instead of [bet]. Also, in many cases he counted syllables instead of sounds or letters. His ability to count the number of syllables was intact.

\subsubsection{Reading and writing}

When reading aloud in Arabic, M.H. demonstrated two strategies. In some cases of single and short words he seemed to use a direct visual strategy, immediately recognizing the word. In other cases this strategy was not successful and he turned to letter-by-letter reading, resulting in literal paralexias (for example, the word a'melat, "workers," was read as a'lamat, which is not a meaningful word), but often he recognized this immediately and corrected himself. His strategy for reading in Hebrew was similar, but his performance was poor, probably because of the general inappropriateness of letter-by-letter reading for unvoweled Hebrew (see Birnboim, 1995). His spontaneous writing (in Arabic) was good at the level of single words and word combinations without literal paragraphias. In Hebrew, he was able to write to dictation only at the level of words with literal paragraphias (for example, the word mapa, "map," was written as maba, which is not a meaningful word). 
As can be seen from the tests administered in two languages, M.H. displayed different symptomatologies in the two languages, with the language impairment significantly more prominent in Hebrew. This was an interesting development. Arabic is structurally not very distant from Hebrew, especially in morphology and syntax. It is important to remember that, although Arabic is M.H.'s native language, he had nearly equivalent proficiency in the two languages prior to his illness. During the period of language therapy, the various tests administered to determine the nature of his impairments yielded an initial diagnosis of amnestic aphasia.

One of the important pieces of information in M.H.'s case is the localization of the brain injury. He had apparently suffered at least three distinct neurological insults during his hospitalization - herpes encephalitis with intraparenchymal hemorrhage into the left temporal lobe, right frontal subdural hematoma, and epileptic seizures - in addition to undergoing emergency surgical craniotomy of the presumably dominant hemisphere. As each insult involves distinct language networks, a detailed account of the patient's clinical language deterioration as it relates to these insults will illuminate the complex representation of more than one language in the brain, and the process of speech perception and production.

Herpes encephalitis is known to involve the bilateral temporal lobes. Among other functions, these lobes are critical in short-term memory consolidation (hippocampus) and naming functions (dominant hemisphere middle and superior temporal gyrus) (Gleissner, et al., 1997). The timing and the nature of the patient's language deterioration (detailed above) support the involvement of bilateral temporal lobes. This conclusion is in line with studies on the language organization of the temporal lobe, particularly with respect to the anatomy of the superior and middle temporal gyrus (Janszky, et al., 2004). The potentially aneurismal subrachnoid hemorrhage M.H. suffered may be associated with delayed ischemic deficits, vasospasm, and distal thromboembolic events, and might be related to the language symptoms.

Attempts have been made to explain the major aphasia syndromes, such as that seen in our patient. Evidence has accumulated over the past 30 years in support of the dissociation between languages (Caramazza \& Zurif, 1976; Dehaene, Dupoux \& Mehler, 1997; Green \& Price, 2001): that is, that the performance of aphasic patients on some linguistic tasks may vary across languages. Researchers have turned to the nature of language representation in an attempt to explain this finding. One approach suggests that L1 and L2 representations are, to some extent, sustained by different brain areas. Another suggests that L2 representations are organized according to exactly the same principles as those governing L1 organization, which means that the two representations are sustained by the same brain areas.

Because the lexical representations of the two languages would be governed by variables such as grammatical class and semantic category regardless of language membership, this approach does not rule out the possibility that a bilingual aphasic may selectively recover one language and lose the other (see Green, 2005; Green \& Price, 2001). M.H.'s performance on the naming tasks suggests that his naming difficulties probably stemmed from damage to a lexical retrieval mechanism. However, not all linguistic components (like naming) are similar in the two languages. As described above, once the target lexical node is selected, the next step in speech production is the selection of the word's phonological segments. The dynamics of the activation and selection of the phonological component of words vary 
widely between models. One of the major differences is the extent to which the models implement the spreading activation principle between the lexical layer and the phonological layer. Although the principle has been widely adopted when characterizing the dynamics of processing between the semantic level and the lexical level, it is not as widely employed when characterizing processing at the segmental phonological level. According to discrete stage models of lexical access (Levelt, 1989; Levelt et al., 1999), the activation of phonological properties is restricted to those of the selected lexical node. Furthermore, the activation of the phonological properties of words begins only after the target lexical node has been selected. In contrast, the cascaded models of lexical access (Caramazza, 1997; Dell et al., 1997) assume that all the lexical nodes activated from the semantic level send proportional activation to their phonological segments. Furthermore, the activation of the phonological properties of words occurs before lexical selection takes place.

\section{Conclusions}

This chapter shows how encephalitis can induce different types of damage to the cognitive system. In the context of the bilingual brain, and according to previous findings from behavioral cognitive studies (Ibrahim \& Aharon-Peretz, 2005; Ibrahim, 2009b), the different impairments in L1 and L2 seen in our bilingual patient suggest that representations of LI and L2 are, to some extent, sustained by different brain areas, and that a common semantic system is connected to two independent lexical systems corresponding to each of the two languages known by the bilingual. Given that M.H. had residual brain damage, and evinced more deficits in L2 perception and production than L1, the data support this position. This study of a bilingual native Arab speaker who acquired Hebrew (also a Semitic language), together with experimental neurolinguistic data gathered from both the patient and the literature, is a valuable combination for elucidating the relationship between language and mechanisms of neurobiology. Further, the combination provides psycholinguistic evidence by which to understand the dynamics of processing two languages in bilingual patients.

Our findings raise a number of questions: Does this specific mechanism function very early during language acquisition? Does the availability of this mechanism depend on the age of L2 acquisition (in childhood or adulthood)? These and other questions remain to be addressed in the study of representation of more than one language in the brain, and of the mechanisms of speech perception and production.

\section{References}

Albert, M. L., Goodglass, H., Helm, N. A., Runens, A. B., \& Alexander, M. P. (1981). Clinical Aspects of Dysphasia. New York: Springer-Verlag.

Birnboim, S. (1995). Acquired surface dyslexia: the evidence from Hebrew. Applied Psycholinguistics, 16, 83-102.

Boivin M.J. (2002). Effects of early cerebral malaria on cognitive ability in Senegalese children. Journal of Developmental Behavioral Pediatrics, 23(5), 353-364.

Caramazza, A. (1997). How many levels of processing are there in lexical access? Cognitive Neuropsychology, 14, 177-208.

Caramazza, A., and E. B. Zurif. (1976). Dissociation of algorithmic and heuristic processes in sentence comprehension: evidence from aphasia. Brain \& Language, 3, 572 -582. 
Carter, J A, Murira, G M, Ross, A J., Mung'ala-Odera, V., \& Newton, C.R. (2003). Speech and language sequelae of severe malaria in Kenyan children. Brain Injury, 17(3),217-224.

Carter, J.A, Neville, B.G., \& Newton, C.R. (2003). Neuro-cognitive impairment following acquired central nervous system infections in childhood: a systematic review. Brain Research Brain Research Reviews, 43(1), 57-69.

Carter, J.A., Mung'ala-Odera, V., Neville, B.G., Murira, G., Mturi, N., Musumba, C., \& Newton, C.R. (2005a). Persistent neurocognitive impairments associated with severe falciparum malaria in Kenyan children. Journal of Neurology, Neurosurgery and Psychiatry, 76(4), 476-481.

Carter, J.A., Ross, A.J., Neville, B.G., Obiero, E., Katana, K., Mung'ala-Odera, V., Lees, J.A., \& Newton, C,R, (2005b). Developmental impairments following severe falciparum malaria in children. Tropical Medicine \& International Health, 10(1), 3-10.

Dehaene. S., Dupoux. E., \& Mehler. J. (1997). Anatomical variability in the cortical representation of first and second language. Neuroreport, 8(17), 3809-3815.

Dell, G. S., Schwartz, M. F., Martin, N. M., Saffran, E. M., \& Gagnon, D. A. (1997). Lexical access in aphasic and nonaphasic speakers. Psychological Review, 104(4), 801-838.

Green, D. W. (2005). The neurocognition of recovery patterns in bilingual aphasics. In J. F. Kroll, \& A. M. B. de Groot (Eds.), Handbook of Bilingualism: Psycholinguistic Approaches (pp. 516-530). New York: Oxford University Press.

Green, D. W., \& Price, C. J. (2001). Functional imaging in the study of recovery patterns in bilingual aphasia. Bilingualism. Language and Cognition, 4, 191-201.

Gleissner, U., Helmstaedter, C., Kurthen, M., \& Elger C. E. (1997). Evidence of very fast memory consolidation: an intracarotid amytal study. Neuroreport, 8(13):2893-6.

Heaton, R. K., Chelune, G. J., Talley, J. L., Kay, G. G., \& Curtis, G. (1993). Wisconsin Card Sorting Test Manual: Revised and Expanded. Odessa, FL: Psychological Assessment Resources.

Holding, P A, Stevenson, J, Peshu, N, Marsh, K (1999). Cognitive sequelae of severe malaria with impaired consciousness. Transactions of the Royal Society of Tropical Medicine and Hygiene, 93(5), 529-534.

Ibrahim, R. \& Aharon-Peretz, J. (2005). Is literary Arabic a second language for native Arab speakers?: Evidence from a semantic priming study. The Journal of Psycholinguistic Research, 34(1),51-70.

Ibrahim, R. (2009a). Selective deficit of second language: A case of Arabic-Hebrew bilingual brain-damaged patient. Behavioral and Brain Functions. 5 (17).1-10.

Ibrahim, R. (2009b). The cognitive basis of diglossia in Arabic: Evidence from a repetition priming study within and between languages. Psychology Research and Behavior Management. 12, 95-105.

Idro, J.A, Carter, G., Fegan, B. G., Neville, G.R., \& Newton, C.R.J.C. (2006). Risk factors for persisting neurological and cognitive impairments following cerebral malaria. Archive of Disease in Childhood, 91(2), 142-148.

Idro, R., Karamagi, C., \& Tumwine, J. (2004). Immediate outcome and prognostic factors for cerebral malaria among children admitted to Mulago Hospital, Uganda. Annals of Tropical Paediatrics, 24(1), 17-24.

Janszky, J., Jokeit, H., Heinemann, D., Schulz, R., Woermann, F. G., \& Ebner, A. (2004). Epileptic activity influences the speech organization in medial temporal lobe epilepsy. Brain, 127(7): 1518 - 1525 
Johnston, F.E., Low, S.M., de Baessa, Y., \& MacVean, R.B. (1987). Interaction of nutritional and socioeconomic status as determinants of cognitive development in disadvantaged urban Guatemalan children. American Journal of Physical Anthropology, 73, 501-506.

Kaplan, E., Goodglass, H., \& Weintraub, S. (1983). Boston Naming Test. Philadelphia: Lea and Febiger.

Kertesz, A. (1982). Western Aphasia Battery. New York: Grune and Stratton.

Levelt, W. J. M. (1989). Speaking: From Intention to Articulation. Cambridge, MA: MIT Press.

Levelt, J. M. W., Roelofs, A., \& Meyer, A. S. (1999). A theory of lexical access in speech production. Behavioural and Brain Sciences, 22(1), 1-75.

Luria, A. R., (1970). Traumatic Aphasia: its Syndromes, Psychology, and Treatment. The Hague: Mouton.

Meyers, J.E, \& Meyers, K. R. (1995). Rey Complex Figure Test and Recognition Trial:Professional Manual. Odessa. FL: Psychological Assessment Resources.

Neumann, C., McDonald, M.A., Sigman, M., \& Bwido, N. (1992). Medical illness in schoolage Kenyans in relation to nutrition, cognition, and playground behaviors. Journal of Developmental and Behavioral Pediatrics, 13(6), 392-398.

Pennington, L., Goldbart, J., \& Marshall, J. (2004). Speech and language therapy to improve the communication skills of children with cerebral palsy. Cochrane Database System Review, CD003466.

Walther, F.J., \& Ramaekers, L.H. (1982) Language development at the age of 3 years of infants malnourished in utero. Neuropediatrics, 13(2),77-81.

Wilson, B. I.-C. R., \& Aldrich, F. (1991) The Rivermead Behavioural Memory Test for Children, 2nd edn. Bury St Edmunds: Thames Valley Test Company. 


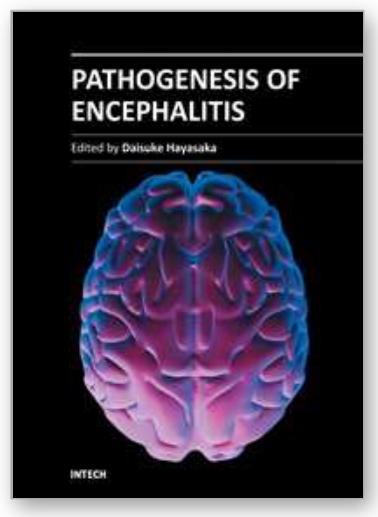

\author{
Pathogenesis of Encephalitis \\ Edited by Dr. Daisuke Hayasaka
}

ISBN 978-953-307-741-3

Hard cover, 344 pages

Publisher InTech

Published online 09, December, 2011

Published in print edition December, 2011

Many infectious agents, such as viruses, bacteria, and parasites, can cause inflammation of the central nervous system (CNS). Encephalitis is an inflammation of the brain parenchyma, which may result in a more advanced and serious disease meningoencephalitis. To establish accurate diagnosis and develop effective vaccines and drugs to overcome this disease, it is important to understand and elucidate the mechanism of its pathogenesis. This book, which is divided into four sections, provides comprehensive commentaries on encephalitis. The first section ( 6 chapters) covers diagnosis and clinical symptoms of encephalitis with some neurological disorders. The second section ( 5 chapters) reviews some virus infections with the outlines of inflammatory and chemokine responses. The third section ( 7 chapters) deals with the non-viral causative agents of encephalitis. The last section ( 4 chapters) discusses the experimental model of encephalitis. The different chapters of this book provide valuable and important information not only to the researchers, but also to the physician and health care workers.

\title{
How to reference
}

In order to correctly reference this scholarly work, feel free to copy and paste the following:

Raphiq Ibrahim (2011). Language and Cognitive Impairments Associated with Encephalitis, Pathogenesis of Encephalitis, Dr. Daisuke Hayasaka (Ed.), ISBN: 978-953-307-741-3, InTech, Available from:

$\mathrm{http}: / / \mathrm{www}$.intechopen.com/books/pathogenesis-of-encephalitis/language-and-cognitive-impairmentsassociated-with-encephalitis

\section{INTECH}

open science | open minds

\section{InTech Europe}

University Campus STeP Ri

Slavka Krautzeka 83/A

51000 Rijeka, Croatia

Phone: +385 (51) 770447

Fax: +385 (51) 686166

www.intechopen.com

\section{InTech China}

Unit 405, Office Block, Hotel Equatorial Shanghai

No.65, Yan An Road (West), Shanghai, 200040, China

中国上海市延安西路65号上海国际贵都大饭店办公楼405单元

Phone: +86-21-62489820

Fax: $+86-21-62489821$ 
(C) 2011 The Author(s). Licensee IntechOpen. This is an open access article distributed under the terms of the Creative Commons Attribution 3.0 License, which permits unrestricted use, distribution, and reproduction in any medium, provided the original work is properly cited. 